\title{
Cross-legged sitting posture effect on lumbar proprioception in young adults: a cross-sectional study
}

\author{
Rania N. Karkousha, Aseel Rasheed Mohamed ${ }^{*}$ and Amal H. M. Ibrahim
}

\begin{abstract}
Background: The cross-legged sitting posture (CLS) is assumed by young adults' results in a bent and unbalanced posture. The study purpose was to assess the effect of sitting in a cross-legged position (knee on knee) on lumbar proprioception. Thirty-six participants of both genders aged from 18 to 25 were selected and divided equally into group A who adapt to a cross-legged sitting posture and group B who adapt to erect sitting (not prefer crosslegged sitting). The Biodex System 3 pro isokinetic dynamometer was utilized to assess the lumbar proprioception by testing the lumbar region repositioning accuracy.

Results: The lumbar repositioning error of group A increased statistically significantly as compared to group B ( $p<$ 0.05).

Conclusions: Cross-legged sitting posture negatively affects lumbar proprioception compared with participants who adapt to erect sitting, and this effect should be considered in the avoidance of sitting in a cross-legged position and in prevention and intervention programs of lumbar proprioception impairment.
\end{abstract}

Keywords: Cross-legged sitting posture, Lumbar proprioception, Repositioning error, Biodex Isokinetic System

\section{Background}

Young adults and adolescents spend a long time sitting due to sedentary lifestyles which are exacerbated. Most young adults rely on automobiles, even for shortdistance transport, and work or play video games on computers and other screen time activities like watching television [1], and sitting while maintaining knees crossed is an example of popular asymmetric sitting positions [2].

Cross-legged sitting posture has several physiological benefits, such as reducing external and internal obliques muscle fatigue and providing sacroiliac joint stability [3], and subject may find it comfortable, but when an asymmetric position becomes habitual, it has the potential to cause musculoskeletal symptoms and disease [4].

\footnotetext{
* Correspondence: selanida8@gmail.com

Department of Basic Science of Physical Therapy, Faculty of Physical Therapy, Cairo University PT, 7 Ahmed Elzayad, Dokki, Giza 12613, Egypt
}

Proprioception is an essential aspect of the somatosensory system that gives afferent information on joint position and movement in normal human performance [5]. It plays major functions in feedback control, as well as muscle stiffness management. All of these factors have a role in maintaining joint stability. Musculoskeletal problems such as pain and fatigue have caused proprioception dysfunction [6].

The Biodex System 3 isokinetic dynamometer measures the position sensation mechanically accurately [7]. The active reposition sense was evaluated perfectly using Biodex System since it indicates functional use and is not affected by the external pressure of the measurement equipment on the body [8].

Previous studies were done by Jung et al. [9] on sixty participants to assess the cross-legged sitting effects on the obliquity of the pelvic and revealed increased pelvic asymmetry due to cross-legged sitting. Areeudomwong et al. [10] investigated twenty-three participants to assess

\section{Springer Open}

(ㅇ The Author(s). 2021 Open Access This article is licensed under a Creative Commons Attribution 4.0 International License, which permits use, sharing, adaptation, distribution and reproduction in any medium or format, as long as you give appropriate credit to the original author(s) and the source, provide a link to the Creative Commons licence, and indicate if changes were made. The images or other third party material in this article are included in the article's Creative Commons licence, unless indicated otherwise in a credit line to the material. If material is not included in the article's Creative Commons licence and your intended use is not permitted by statutory regulation or exceeds the permitted use, you will need to obtain permission directly from the copyright holder. To view a copy of this licence, visit http://creativecommons.org/licenses/by/4.0/. 
the seated handicraft tasks' effects on trunk muscle fatigue. They revealed that during $30 \mathrm{~min}$ of sitting, the crossed-leg sitting posture caused trunk muscular fatigue.

Individuals with low lumbar extensor muscular endurance will have an influence on posture and balance because they are connected with poor proprioceptive input from the muscles, which can cause back pain [11]. Van der Esch et al. [12] reported that back muscular weakness was found to impact the trunk proprioceptive or mechanoreceptor signals' postural strategy.

Several studies had been conducted to determine the morphological and functional changes in people who adapted to sitting in a cross-legged position, but there was a literature gap in the effect of sitting in a crosslegged position on lumbar proprioception.

\section{Methods}

\section{Participants}

Thirty-six students of both genders from Cairo University's Faculty of Physical Therapy were recruited (mean age $22.61 \pm 1.89$ years, height $169.41 \pm 7.87 \mathrm{~cm}$, weight $65.61 \pm 8.065 \mathrm{~kg}$ ), and BMIs were less than $25 \mathrm{~kg} / \mathrm{m}^{2}$. The G* POWER statistical software (version 3.1) was used to determine the size of the sample (Franze faul, Universtat akiel, Germany).

Participants were divided into group A including 18 participants who adapted to cross-legged posture for at least $3 \mathrm{~h}$ per day for at least 1 year and group B including 18 participants who adapted to erect sitting.

Participants with a history of upper or lower extremity neurological disorders, visual or vestibular problems, radiculopathy, or back surgery, as well as pregnant females, were excluded from the study.

\section{Design of the study}

This is an observational cross-sectional study. The study was done at the Laboratory of Isokinetic at Cairo University's Faculty of Physical Therapy from December 2020 to June 2021. The assessment was done once for all participants.

\section{Instrumentations \\ Weight and height scale}

It was used to measure the height and weight of the participants and calculate the BMI $\left(\mathrm{BMI}=\mathrm{kg} / \mathrm{m}^{2}\right)$.

\section{Biodex System 3 pro isokinetic dynamometer}

The dynamometer with a specific reclining back attachment is designed to assess the lumbar region's repositioning accuracy (Biodex Medical INC., Shirley, NY, USA). Its validity is ICC $=0.99$ and reliability is $\mathrm{ICC}=$ 0.99 for evaluating joint position sensation [7].

\section{Procedures}

\section{Measurement procedures}

Before beginning the procedures of the study, ethics approval from Cairo University's Faculty of Physical Therapy (NO: P. T. REC/012/002840) was acquired, as well as a completed written consent form from the participants. The participants' ages were recorded, as well as their heights and weights. Enough information was given to the participants about the aim and procedure of the study. Testing active repositioning of the lumbar spine is at $30 \%$ [13].

During the training, the participants were instructed to maintain a specific spinal range of motion, which ranged from neutral extension of the lumbar spine to $30^{\circ}$ flexion. This range was chosen because of the ability of all participants to do it [14]. Three trials were recorded for each participant.

Before each testing session, the Biodex System was calibrated and stabilized. All the participants' ability to do the required lumbar flexion range was assessed. Each participant was seated in the Biodex device chair in a neutral upright starting position. The feet were kept off the floor, and two belts were stabilizing both thighs. The pelvic brace was put on the superior aspect of the proximal aspect of the thighs superiorly, tightly but comfortably. The lumbar spine was additionally supported by a pad. Both hands were crossed over the chest.

The straps of force application were put vertically on the anterior chest wall, and the trunk upper part was connected to the back attachment with a belt, and the head was in a neutral position. By adjusting the seat, align the actuator arm axis with the disc space between L5/S1. In each of the three testing trials, lock the dynamometer in the $0^{\circ}$ position to guarantee that each participant began in the same position.

\section{Pretesting and familiarization}

Two familiarization trials prior to data collection were allowed for all participants, with open eyes. The device moved the trunk to the target lumbar flexion angle $\left(30^{\circ}\right)$ [14] then held it for $5 \mathrm{~s}$ to allow enough time for the participant to remember the position and replicate it with closed eyes [15]. The device then allowed the trunk to get back to the beginning point.

\section{Lumbar repositioning accuracy test}

The device moved the trunk to $30^{\circ}$ of lumbar flexion, then held it at this angle for $5 \mathrm{~s}$. The participant was then told to get back to the beginning point and actively recreate the target angle as precisely as possible. When the participant felt he or she had achieved the correct target, the participant kept this position $3 \mathrm{~s}$ before pressing a hold button to record the replicated position. There is a 10-s break between test three trials. The 
proprioceptive error was measured in degrees as the absolute error using the three trials' mean angular difference between the target angle position and the participant's perceived angle position [16].

\section{Statistical analysis}

The Shapiro-Wilk test was utilized to check the normality of the data. The characteristics of participants and joint position error were compared between the groups using an unpaired $t$ test. The Statistical Program for Social Studies (SPSS) version 25 for Windows was used for all statistical analysis (IBM SPSS, Chicago, IL, USA). For all statistical tests, the significance level was set at $p<0.05$.

\section{Results}

\section{Characteristics of participants}

There was no significant statistical difference between both groups in the mean age, weight, height, BMI, and sex distribution $(p>0.05)$ (see Table 1).

\section{Effect of cross-legged sitting position on joint position error}

Group A had a mean $\pm S D$ joint position error of $5.72 \pm$ $1.71^{\circ}$, while group $\mathrm{B}$ had a mean $\pm S D$ joint position error of $4.07 \pm 1.68^{\circ}$. The mean difference between both groups was $1.65^{\circ}$. There was a significant increase in the joint position error of group A in comparison with that of group B ( $p=0.006)$ (see Fig. 1).

\section{Discussion}

The study was conducted to assess the effect of sitting in a cross-legged position on lumbar proprioception in young adults. When comparing groups $\mathrm{A}$ and $\mathrm{B}$, the study found that group A had a much higher lumbar repositioning error.

The study's findings can be attributed to one of the following mechanisms. First, sitting cross-legged causes a bent and imbalanced posture, resulting in a considerable increase in pelvic obliquity [9]. Lumbar proprioception impairment is assumed to affect the spinal control by reducing the capacity to achieve

Table 1 Comparison of characteristics of participants between group $A$ and group $B$

\begin{tabular}{lllllll}
\hline & Mean \pm SD & & MD & $\boldsymbol{t}$-value & $\boldsymbol{p}$-value \\
\cline { 2 - 3 } & Group A & Group B & & & \\
\hline Age (years) & $22.17 \pm 2.17$ & $23.05 \pm 1.61$ & -0.88 & -1.37 & $0.18^{*}$ \\
Weight $(\mathbf{k g})$ & $65.22 \pm 8.98$ & $66 \pm 7.15$ & -0.78 & -0.28 & $0.77^{*}$ \\
Height $(\mathbf{c m})$ & $169.72 \pm 8.18$ & $169.11 \pm 7.56$ & 0.61 & 0.23 & $0.81^{*}$ \\
BMI (kg/m $\left.\mathbf{m}^{2}\right)$ & $22.56 \pm 1.75$ & $23.05 \pm 1.61$ & -0.49 & -0.87 & $0.38^{*}$ \\
\hline
\end{tabular}

$S D$ standard deviation, $M D$ mean difference

*Non-significant normal posture of the spine and adequately coordinate muscle activity [17]. Impairment in lumbar proprioception with cross-legged sitting posture can be a viable cause for the development of spine mal-posture in those individuals.

Second, the finding might be attributed to the impairment of proprioceptive sense, and coordination ability, athletic activities, daily life, and rehabilitation treatments resulted from muscle fatigue [18], which results after 30 min of crossed-leg sitting posture [10].

Third, sitting in an unequal position for a long period of time causes back pain [19]. The lumbar proprioceptive sense is diminished in people who experience non-specific low back pain [20], and pain inhibition of local muscles like the lumbar multifidus can cause changes in the muscle recruitment patterns, affecting the neuromotor system, altering dynamic spine stabilization, and resulting in repositioning deficiencies, as seen by the low back pain that arose from sitting cross-legged for a prolonged time can produce alterations in spinal posture, indicating the possibility of pelvic pain [15, 21], and Röijezon et al. [6] reported that altered proprioception has been linked to pain.

Fourth, this finding could be due to a deficit in the passive component of the stability system of the lumbar spine (spinal column), which occurs after assuming a cross-legged sitting posture that can produce pelvic posterior rotation, resulting in reduced sacral inclination [22], and the lateral pelvic tilt revealed significant variations in participants who adapted crosslegged sitting posture, indicating the likelihood of spinal lateral flexion [21].

The present finding is supported by Tong et al. [23], who systematically reviewed the lumbar proprioception and low back pain relationship and revealed that deficit with lumbar proprioception could be mediated by encouraging people to adopt and maintain bad postures. This is also agreed with O'Sullivan et al. [15] who conducted their study on thirty participants to determine the effect of lumbar segmental instability on lumbar proprioception in a neutral spinal position and believed that those who adopt a crosslegged sitting posture have trunk muscle dysfunction which could lead to a change in the affected muscle's normal afferent input.

The finding of this study, however, differs from the earlier finding of Newcomer et al. [24], who found no major difference in proprioceptive error between individuals with low back pain appearing in cross-legged sitting posture adapters and control subjects. The researchers identified the measurement of the lower limbs technique was not precise enough. 


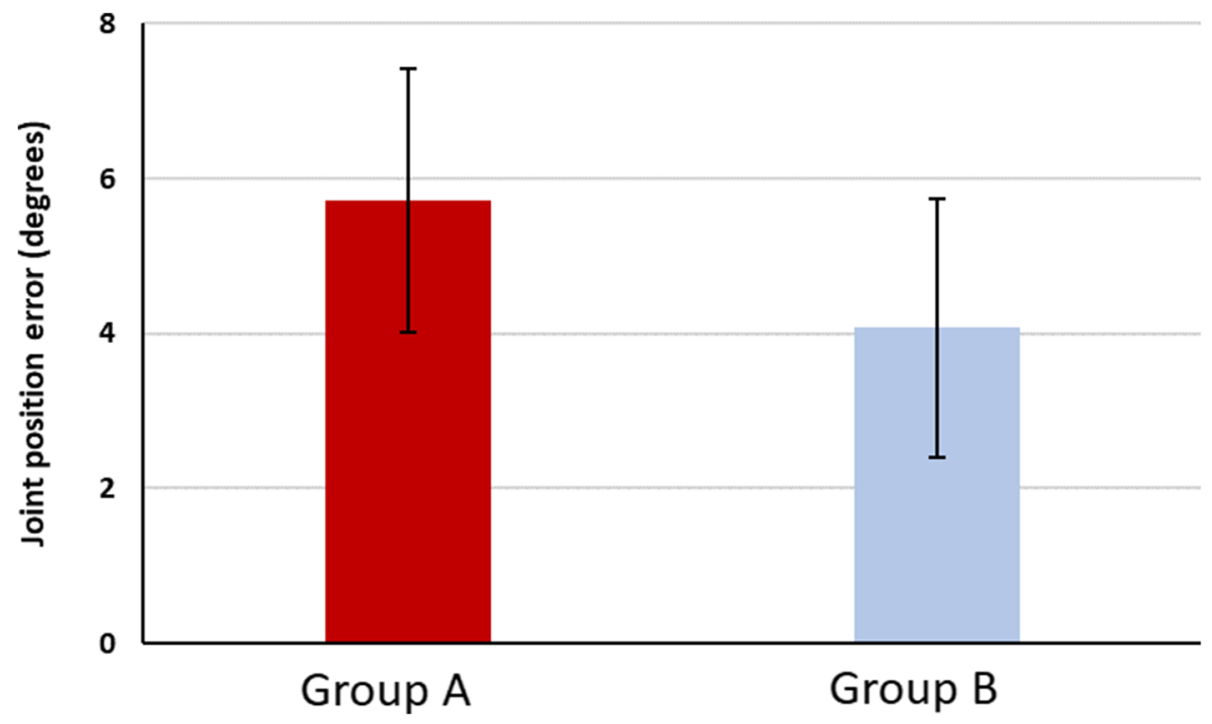

Fig. 1 Mean joint position error of groups A and B

\section{Limitations of the study}

The study limitation was the inability of the Biodex System 3 to detect fractions of degrees, influencing the accuracy of measurement.

The study recommends that people who have adapted to the cross-legged sitting posture should avoid it or at least reduce the time of assuming it due to its bad side effects. Studies should be done in the future to assess the effect of cross-legged sitting posture on proprioception of other joints and the effect of cross-legged sitting posture on lumbar proprioception in elderly people.

\section{Conclusions}

According to the study findings, there is a decrease in lumbar repositioning accuracy of participants who adapted to sitting in a cross-legged position for at least $3 \mathrm{~h}$ a day for at least 1 year compared with those who adapted to erect sitting posture, and this effect should be considered in the avoidance of sitting in a cross-legged position and in prevention and intervention programs of lumbar proprioception impairment.

\section{Abbreviation}

CLS: Cross-legged sitting

\section{Acknowledgements}

N/A

\section{Authors' contributions}

The authors satisfy that all persons designated as authors qualify for authorship. The manuscript's content and similarity index are the responsibility of all authors who have critically reviewed and approved the final version.

\section{Funding}

Nil
Availability of data and materials

The data collected and analyzed during the study are available from the corresponding author on reasonable request and after institutional approval.

\section{Declarations}

Ethics approval and consent to participate

Before beginning the study procedures, ethics approval from Cairo University's Faculty of Physical Therapy (NO: P. T. REC/012/002840) was acquired, as well as a completed written consent form from the participants.

\section{Consent for publication}

N/A

\section{Competing interests}

The authors declare that they have no competing interests.

Received: 30 July 2021 Accepted: 18 September 2021

Published online: 19 November 2021

\section{References}

1. Hadgraft NT, Lynch BM, Clark BK, Healy GN, Owen N, Dunstan DW. Excessive sitting at work and at home: correlates of occupational sitting and TV viewing time in working adults. BMC Public Health. 2015;15(1):1-3. https:// doi.org/10.1186/s12889-015-2243-y.

2. Anwary $A R$, Bouchachia $H$, Vassallo $M$. Real time visualization of asymmetrical sitting posture. Procedia Comput Sci. 2019;155:153-60. https:// doi.org/10.1016/j.procs.2019.08.024.

3. Snijders CJ, Hermans PFG, Kleinrensink GJ. Functional aspects of crosslegged sitting with special attention to piriformis muscles and sacroiliac joints. Clin Biomech (Bristol, Avon). 2006; 21:116-121.

4. Woo HS, Oh JC, Won SY. Effects of asymmetric sitting on spinal balance. J Phys Ther Sci. 2016;28(2):355-9. https://doi.org/10.1589/jpts.28.355.

5. Relph $\mathrm{N}$, Herrington $\mathrm{L}$, Tyson $\mathrm{S}$. The effects of $\mathrm{ACL}$ injury on knee proprioception: a meta-analysis. Physiotherapy. 2014;100(3):187-95. https:// doi.org/10.1016/j.physio.2013.11.002.

6. Röijezon U, Clark NC, Treleaven J. Proprioception in musculoskeletal rehabilitation. Part 1: Basic science and principles of assessment and clinical interventions. Man Ther. 2015;20(3):368-77. https://doi.org/10.1016/j.math.2 015.01.008.

7. Drouin JM, Valovich-mcLeod TC, Shultz SJ, Gansneder BM, Perrin DH. Reliability and validity of the Biodex System 3 pro isokinetic dynamometer velocity, torque and position measurements. Eur J Appl Physiol. 2004;91(1): 22-9. https://doi.org/10.1007/s00421-003-0933-0. 
8. Hillier S, Immink M, Thewlis D. Assessing proprioception: a systematic review of possibilities. Neurorehabil Neural Repair. 2015;29(10):933-49. https://doi.org/10.1177/1545968315573055.

9. Jung $\mathrm{K}-\mathrm{S}$, Jung $\mathrm{J}-\mathrm{H}$, In T-S. The effects of cross-legged sitting on the trunk and pelvic angles and gluteal pressure in people with and without low back pain. Int J Environ Res Public Health. 2020;17(13):4621. https://doi.org/1 0.3390/ijerph17134621.

10. Areeudomwong P, Puntumetakul R, Kaber DB, Wanpen S, Leelayuwat N, Chatchawan U. Effects of handicraft sitting postures on lower trunk muscle fatigue. Ergonomics. 2012;55(6):693-703. https://doi.org/10.1080/00140139.2 012.658086.

11. Reddy RS, Maiya GA, Rao SK. Proprioceptive reposition errors in subjects with cervical spondylosis. Int. j. med. health res. 2012;1:65-73.

12. van der Esch M, Steultjens M, Harlaar J, Knol D, Lems W, Dekker J. Joint proprioception, muscle strength, and functional ability in patients with osteoarthritis of the knee. Arthritis Rheum. 2007;57(5):787-93. https://doi. org/10.1002/art.22779.

13. Mayer TG, Smith SS, Keeley J, Mooney V. Quantification of lumbar function. Part 2: Sagittal plane trunk strength in chronic low-back pain patients. Spine (Phila Pa 1976). 1985; 10:765-772.

14. Wilson SE, Granata KP. Reposition sense of lumbar curvature with flexed and asymmetric lifting postures. Spine (Phila Pa 1976). 2003; 28:513-518.

15. O'Sullivan PB, Burnett A, Floyd AN, Gadsdon K, Logiudice J, Miller D, et al. Lumbar repositioning deficit in a specific low back pain population. Spine (Phila Pa 1976). 2003; 28:1074-1079.

16. Ribeiro F, Oliveira J. Effect of physical exercise and age on knee joint position sense. Arch Gerontol Geriatr. 2010;51(1):64-7. https://doi.org/10.101 6/j.archger.2009.07.006.

17. Dankaerts W, O'Sullivan P, Burnett A, Straker L. Differences in sitting postures are associated with nonspecific chronic low back pain disorders when patients are subclassified. Spine (Phila Pa 1976). 2006; 31:698-704.

18. Marks R. Effect of exercise-induced fatigue on position sense of the knee Aust J Physiother. 1994;40(3):175-81. https://doi.org/10.1016/50004-9514(14 )60576-6.

19. Waongenngarm P, Areerak K, Janwantanakul P. The effects of breaks on low back pain, discomfort, and work productivity in office workers: a systematic review of randomized and non-randomized controlled trials. Appl Ergon. 2018;68:230-9. https://doi.org/10.1016/j.apergo.2017.12.003.

20. Reddy RS, Alahmari KA, Samuel PS, Tedla JS, Kakaraparthi VN,

Rengaramanujam K. Intra-rater and inter-rater reliability of neutral and target lumbar positioning tests in subjects with and without non-specific lower back pain. J Back Musculoskelet Rehabil. 2021;34(2):289-99. https://doi.org/1 0.3233/BMR-200010.

21. Park Y, Bae Y. Comparison of postures according to sitting time with the leg crossed. J Phys Ther Sci. 2014;26(11):1749-52. https://doi.org/10.1589/jpts.2 6.1749 .

22. Watanabe S, Kobara K, Yoshimura Y, Osaka H, Ishida H. Influence of trunk muscle co-contraction on spinal curvature during sitting. J Back Musculoskelet Rehabil. 2014;27(1):55-61. https://doi.org/10.3233/BMR-13 0419.

23. Tong MH, Mousavi SJ, Kiers H, Ferreira P, Refshauge K, van Dieën J. Is there a relationship between lumbar proprioception and low back pain? A systematic review with meta-analysis. Arch Phys Med Rehabil. 2017;98(1): 120-36. https://doi.org/10.1016/j.apmr.2016.05.016.

24. Newcomer K, Laskowski ER, Yu B, Larson DR, An KN. Repositioning error in low back pain: comparing trunk repositioning error in subjects with chronic low back pain and control subjects. Spine (Phila Pa 1976). 2000;25(2):245-50 https://doi.org/10.1097/00007632-200001150-00017.

\section{Publisher's Note}

Springer Nature remains neutral with regard to jurisdictional claims in published maps and institutional affiliations.

\section{Submit your manuscript to a SpringerOpen ${ }^{\circ}$ journal and benefit from:}

- Convenient online submission

- Rigorous peer review

- Open access: articles freely available online

- High visibility within the field

- Retaining the copyright to your article

Submit your next manuscript at $\boldsymbol{\nabla}$ springeropen.com 